\title{
LA VISITACIÓN PASTORAL COMO MÉTODO EFICAZ EN EL CRECIMIENTO INTEGRAL DE LOS MIEMBROS DE IGLESIA
}

\author{
Cristian S. Gonzales Yupanqui \\ Cristian.gonzales@upeu.edu.pe \\ Universidad Peruana Unión
}

El artículo presenta la visitación pastoral como uno de los mejores métodos en crecimiento de integral de los miembros de iglesia: compromiso misionero, fidelidad en la devolución de los diezmos, dadivosidad en las ofrendas y en los proyectos de iglesia y más bautismos como consecuencia.

Palabras clave: Visitación pastoral, crecimiento de iglesia. 


\section{THE PASTORAL VISITATION AS AN EFFECTIVE METHOD IN THE INTEGRAL GROWTH OF CHURCH MEMBERS}

\footnotetext{
Abstract

The article introduce the pastoral visitation as one of the best methods of growing integral members church in missionary commitment, faithfulness in returning tithes and offerings largesse in church projects and resulting baptisms.

Keywords: Pastoral visitation, pastoral care, church growth.
} 


\section{Introducción}

Atender la feligresía de un distrito misionero cada año se torna más difícil, porque los miembros de iglesia cada día están más expuestos a los peligros de una sociedad consumista y atrayente a todo tipo de pecado. Encontrar un método que pueda ayudar en el crecimiento espiritual de los miembros de iglesia es un desafío.

La visitación es uno de los mejores métodos para lograr el crecimiento espiritual de la hermandad. Sin embargo, son pocos los pastores que han conseguido realizar una buena visitación y, como consecuencia, alcanzar un crecimiento integral en sus miembros.
Por lo tanto, surge una pregunta: ¿Cómo se debe realizar una visita con éxito? Esta es una de las preguntas más comunes que se hacen los líderes de iglesia y algunos pastores. Por lo cual, este artículo pretende responder a esta pregunta, con un planteamiento que puede ayudar a realizar una visitación completa e íntegra a favor de los miembros de iglesia. Este tipo de visitación debe ser realizado exclusivamente por el pastor distrital.

\section{La visita pastoral}

Para poder realizar una buena visita pastoral, es necesario utilizar un instrumento, el cual es presentado a continuación:

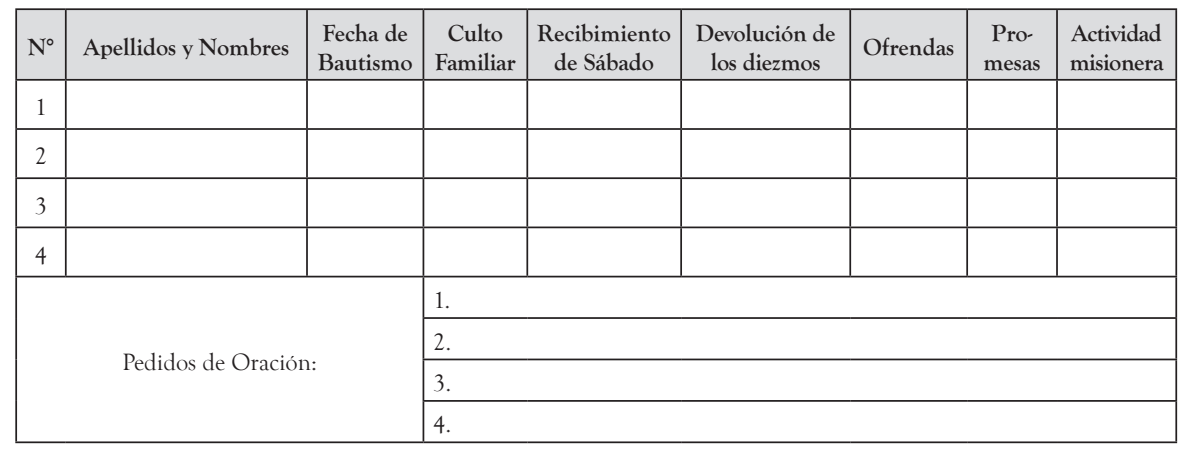


Tabla para realizar una visitación pastoral efectiva denominado cartón de visitación. Esta tabla sencilla, con preguntas sencillas, hará la diferencia en la labor misionera.

\section{Aplicación del instrumento}

En primer lugar, es necesario considerar algunos pasos antes de realizar la visita: (1) La familia debe saber la fecha de la visitación con anticipación, para que todos sus miembros participen, (2) $\mathrm{Si}$ fuera posible, se debe tener un registro con todos los datos de la familia a visitar, (3) Las preguntas son individuales y personales. ${ }^{1}$ En segundo lugar, se debe rellenar el cartón de visitación con mucho cuidado, para no distorsionar la veracidad de las respuestas.

Al ver la tabla presentada, usted se preguntará: ¿cómo esta tabla puede ayudarme? Es sencillo, pero de mucho valor, su aporte será muy significativo si se aplica de una manera correcta. El traba-

${ }^{1}$ Cristian Gonzales, "El verdadero significado de la visitación-Episkopes" Estrategias para el cumplimiento de la misión 12, no. 2 (2014): 72-3. jo no es solo completar los espacios en blanco, sino es realizar un verdadero diagnóstico espiritual en cada persona. Las preguntas son realizadas a todos los miembros, de la familia, uno por uno, sin pasar por alto a ninguno de sus miembros, aunque sean pequeños.

Las preguntas se deben comenzar a realizar por los padres y luego los hijos. A continuación se presentará la forma y la intención de cada pregunta:

1. Fecha de bautismo $(\mathrm{Mr}$ 16:16): Esta pregunta permite darle confianza al miembro de iglesia que es entrevistado. La pregunta se puede hacer de esta manera: ¿Cómo conoció la verdad del evangelio y hace cuánto tiempo Ud. es bautizado? Generalmente las personas reviven con pasión el momento de su bautizo, ellos recuerdan cómo Jesús los rescató del mundo de pecado $(\mathrm{Mr}$ 10:45), después se le puede hacer reflexionar sobre la cantidad de años que la persona tiene en la iglesia, 
y sobre las muchas bendiciones que ha recibido.

¿Por qué es importante hacer esta pregunta?

a. Cuando el pastor llega por primera vez al distrito misionero, desconoce la vida espiritual de sus feligreses, especialmente de aquellos que lideran la iglesia, por tanto, es necesario que el pastor esté seguro de la vida espiritual de sus miembros de iglesia. A que toma tiempo saber $y$, por ende, se cometen errores en las elecciones locales.

b. Para evitar hacer preguntas en el futuro, esta pregunta te permite saber la fecha de su bautismo o su rebautismo.

c. Aunque parece ilógico, algunas veces las personas que se apartaron por años de la iglesia, después de su bautismo, son los que

lideran la iglesia, sin ser guiados de acuerdo al manual de la Iglesia Adventista del Séptimo Día.

2. Culto familiar (Dt 6:5-7): En esta pregunta comienza el diagnóstico espiritual. Una pregunta más completa sería: ¿Cómo, con qué frecuencia, a qué hora y quiénes participan del culto familiar? En esta pregunta los miembros de iglesia reaccionan de dos formas: (1) Las personas se quedan sorprendidas porque, en muchos casos, es la primera vez que alguien les hace una pregunta directa respecto de su vida íntima con Dios, por lo cual, les gustaría que usted les ayude, sino saben cómo hacerlo. (2) Las familias que tienen el hábito de realizar sus cultos familiares, van a desear saber cómo enriquecerlos. Por lo cual, usted debe ir preparado.

¿Por qué es importante hacer esta pregunta? 
a. Porque, en la visitación, el pastor debe brindar toda la ayuda posible a los miembros de iglesia, además, con esta pregunta, se inicia el diagnóstico espiritual. Por tanto, asegúrese de hacer un buen diagnóstico. Dios espera que la influencia de los ministros sea para salvación.

b. Son pocas las veces que un ministro se detiene para hablar acerca del culto familiar en la iglesia. Hablar de este tema, en la casa, tiene consecuencias eternas. Salvar a un persona es una victoria, pero salvar a una familia no tiene comparación.

c. El pastor tiene la mejor oportunidad para ayudar a esa familia. Sus concejos serán muy apreciados por ellos. d. Es el comienzo de la preparación para la segunda venida de Cristo.

3. Recibimiento de Sábado (Lc 23:54): Es una pregunta muy sensible en la vida espiritual de muchos miembros de iglesia. Muchos de ellos se excusan en no poder recibir el sábado a tiempo por tener centros de trabajo lejanos a su casa, de tal manera que, mientras viajan, el sábado llega para muchos. Esta pregunta se puede realizar de otra forma, para tener una respuesta más significativa ¿Cómo, con qué frecuencia, a qué hora y quiénes participan del recibimiento del sábado? Al igual que en la pregunta anterior, los miembros de iglesia van a reaccionar de dos formas: (1) Las personas se sorprenden, ya que en muchos casos a muchos de ellos nunca se les ha hecho ese tipo de preguntas. Como pastor distrital, he podido ver que son muy 
pocas las personas que valoran el recibimiento de sábado y, por ende, sus maravillosas bendiciones. (2) Los pocos miembros de iglesia que tienen el hábito de prepararse, para el día del Señor, también necesitan recibir consejos o sugerencias de cómo enriquecer esa práctica espiritual.

¿Por qué es importante hacer esta pregunta?

a. Si se considera la preparación para el reino de Dios, esta pregunta es muy importante. Aquella persona que no tiene el hábito de prepararse para recibir el sábado, tampoco podrá gozar de las bendiciones del sábado, eso significa que intenta guardar el sábado por razones equivocadas, o no tiene la preparación suficiente para hacerlo.

b. Muchos pastores sufren por la presencia de la hermandad los días sábados por la tarde, eso significa que los miembros de iglesia ignoran los beneficios espirituales del "reposo" espiritual.

c. Si el miembro de iglesia ignora que el sábado es un símbolo de aquel verdadero reposo que será recibido, cuando Cristo regrese por segunda vez, aquel miembro de iglesia no estará preparado para encontrarse con Dios en los cielos.

d. Si el pastor ayuda, a su feligresía, en la preparación para el día sábado, las consecuencias espirituales sobre los miembros de iglesia serán eternas y el crecimiento de la iglesia no tendrá precedentes.

4. Devolución de los diezmos (Mal 3:8-12): esta es una de las preguntas que no les gusta hacer a muchos pas- 
tores, por la reacción que la hermandad tiene acerca de este tema, muchos de ellos piensan que el pastor está interesado solo en el dinero de las personas y no en ellas, de forma especial los tesoreros de iglesia son más sensibles. Sin embargo, cuando la pregunta está bien direccionada no habrá ningún problema de este tipo. El pastor no debe estar interesado en el dinero de la hermandad, sino en la salvación de ella. De acuerdo a Malaquías 3:15: "robará el hombre a Dios, pues vosotros me estáis robando y preguntasteis ¿En qué te estamos robando? En los diezmos y las ofrendas", el profeta Malaquías declara que una persona no puede ser fiel a Dios, sino se devuelve los diezmos. No hay ninguna duda al respecto. Entonces, ¿por qué la hermandad reacciona negativamente cuando se habla del diezmo? Porque ignora que parte de su preparación para el cielo es la devolución del diezmo. Hay dos razones por las cuales un miembro de iglesia debe devolver sus diezmos: (1) Formar, en la persona, el carácter de Dios. A través de la devolución de los diezmos, el ser humano debe aprender a compartir las bendiciones recibidas, el egoísmo debe ser despojado de su vida y debe dejar que el espíritu de liberalidad dirija su vida. (2) Para sostener la iglesia, el pueblo remanente que Dios ha organizado para predicar el evangelio de la segunda venida de Cristo, hasta que el regrese por segunda vez.

¿Por qué es importante hacer esta pregunta?

a. La fidelidad en los diezmos es un asunto de vida o muerte. En el libro de Deuteronomio 28:1-14 se presenta las bendiciones que Dios desea otorgar sobre aquellos que son obedientes a su man- 
dato y también están las maldiciones que caerán sobre aquellos que desobedezcan los mandatos de Dios. Por lo cual, el pastor no debe dejar pasar esta oportunidad para hablar de este tema con la familia visitada.

b. El pastor no debe dudar al hablar de este tema, porque él es el responsable sobre aquellos que están bajo su cuidado. Él tiede: cuidar, apacentar, restaurar y colaborar en la salvación de su pueblo, si el pastor no lo hace, él es culpable por este pecado.

c. Aquel que no devuelve los diezmos es porque todavía no conoce a Dios, por lo tanto, no está preparado para recibir bendiciones mayores.

d. Además, el carácter de

Dios debe ser formado en la vida de cada creyente, el espíritu de liberalidad debe guiar la vida de los hijos de Dios. Aquel que no aprendió a agradecer a Dios por todas las cosas que Él hace en su favor, no podrá ser trasformado a su imagen.

5. La ofrenda ( $\mathrm{Nm}$ 28:1-5): esta es una de las preguntas que muestran el significado que tiene la muerte de Jesús en la cruz del calvario en el adorador. Es importante recordar que Dios fue el primero en darnos un ejemplo en el acto de ofrendar, porqué Él entregó a su Hijo como una ofrenda perfecta por el pecado. Dios no dio algo que le sobraba o alguna criatura que haya sido creada de forma defectuosa, o que no tuviera valor, para que sea el sacrificio por el pecado a favor de la humanidad. La ofrenda, que ofreció Dios, fue perfecta y sin mancha. 
Pero de forma significativa Dios hizo el mayor sacrificio, entregó lo mejor que tenía, ofreció todo lo que tenía, lo arriesgó todo y asimismo, en favor de la humanidad. Por lo tanto, cuando devolvemos las ofrendas debemos hacernos la pregunta: ¿qué clase de ofrenda estamos ofreciendo a Dios?

¿Por qué es importante hacernos esta pregunta?

a. Porque muchos miembros, en las iglesias y congregaciones, piensan que las ofrendas son limosnas que debemos dar para hacer la obra de Dios. Por lo cual, damos a entender que Dios está preocupado por nuestro dinero, sin él, Dios no haría nada a favor del ser humano. Pero, ¿cuánto valor puede tener nuestras monedas? O dicho de otra manera ¿puede algún sacrificio humano compararse con el sacrificio que realizó Jesús? No hay nada humano que pueda compararse con la ofrenda realizada por Dios, aun cuando el ser humano pueda dar todo el dinero de esta tierra, sería insuficiente.

b. Los miembros de iglesia deben entender el valor de este concepto teológico. Así, como hay una preocupación en devolver los diezmos, también debe haber una preocupación en dar las ofrendas de forma sistemática.

c. La dadivosidad en las ofrendas son el resultado de una íntima relación con Dios, como un acto de gratitud y reconocimiento de su señorío en proteger, cuidar, alimentar, sostener y dirigir a sus hijos en todo momento, lugar y bajo toda circunstancia de vida. 
c. Finalmente, la dadivosidad prepara al pueblo de Dios para la segunda venida de Jesús, permite que el carácter sea amoldado a su imagen. El principio bíblico se debe cumplir en la experiencia de cada uno de sus hijos. "Más bienaventurado es dar que recibir" (Hch 20:35), la ley del cielo es dar, todo lo que Dios ha creado tiene algo que dar, por lo tanto, atrévete a experimentar esta promesa en tu vida y atrévete a conocer a Dios!

6. Promesas (Éx 25:1-7. Donativos para proyectos especiales que cada iglesia tiene): en esta sección hay que destacar el rol del miembro de iglesia frente a su iglesia local. Cada iglesia tiene sus propios proyectos como construcción, refracción, implementación, renovación, compra de terreno, proyectos misioneros, etc. Por lo tanto, es imposible que, en una iglesia dinámica y viva, no haya proyectos. Es necesario que cada miembro de iglesia tenga compromiso con ella y pueda colaborar en estos proyectos. Entonces, la pregunta vuelve a levantarse ¿más dinero? Aunque cueste entenderlo, es necesario hacer la siguiente pregunta: ¿dónde está tu corazón? $\mathrm{Si}$ es con Dios, entonces porque no te atreves a dar más de lo que estamos acostumbrados.

¿Por qué es importante esta pregunta?

a. Muchos miembros de iglesia piensan que todo lo que ellos tienen les pertenece, son de ellos, es producto de su sacrificio adquirido a lo largo de toda su vida. Esta forma de pensar ignora a Dios. Colosenses 1: 16, 17, menciona que todo fue hecho por Él y para Él. Entonces, las facultades físicas, mentales 
y espirituales que poseen cada persona fue por gracia divina, no es propiedad exclusiva de cada persona. Todo lo que cada persona ha recibido fue otorgado por Dios, cada ser humano es mayordomo de los bienes de Cristo.

b. Es significativo hacer la siguiente pregunta: iA qué clase de Dios adoramos?, si es un dios endeble, mendigo, sin poder, sin fuerza, entonces él necesita el dinero de la gente para cumplir con sus propósitos. Aunque parezca increíble los miembros de iglesia tienen ese concepto de Dios. ¿cuántas iglesias hay, en cada ciudad, que llevan años sin poder terminar su construcción?, ¿cuántos proyectos se plantean realizar las iglesias, y cuántos se completan? Es increíble, porque son contadas las iglesias que han podido completar la construcción de sus templos, o completar con sus proyectos.

c. Los dones otorgados por Dios a sus hijos son usados para sostener la gran empresa de satanás, por lo cual, cada vez crecen más las olas de violencia, terror, etc. ¿cuántos cines, restaurantes de comida chatarra, cuántas discotecas, cuántos licorerías, cuántos hospedajes, etc. se abren cada año? Es increíble, pero estas empresas progresan a una velocidad cada vez mayor, porque muchas personas son sus clientes. Sin embargo, ¿cuántas iglesias se abren cada año? El dinero es depositado en las empresas satánicas y no en la empresa de Dios.

d. Las personas de fuera deben contemplar a Dios a través de su 
pueblo, entonces, las fachadas, los baños, el salón, los equipos de las iglesias deben ser mejorados, todo debe mostrar un Dios todopoderoso y no lo contrario. Para que eso acontezca, la soberanía de Dios se debe vivir en cada casa. Los miembros de iglesia deben conocer de cerca a Dios, y podrán comprobar que Dios desea lo mejor para sus hijos (3 Jn 2). La prosde la fidelidad y dependencia de Dios.

7. Actividad misionera (Mt 28:19,20): Es claro que el llamado como cristianos es anunciar y proclamar las buenas nuevas a otras personas (Mt 28:18, Ap 14:6). El anuncio, de este mensaje, debe comenzar con el prójimo más cercano, con aquellos que viven en el mismo entorno y que todavía no han entregado su vida a Dios. Si cada

miembro de iglesia es animado a buscar la salvación de sus familiares, la iglesia crecería mucho más rápido. El principal problema de los miembros de iglesia está en encontrar formas y maneras de cómo acercar a sus familiares a los pies de Jesús.

¿Por qué es importante esta pregunta?

a. Uno de los desafíos más grandes, que enfrentan los pastores, es involucrar a la hermandad en la actividad misionera. Este es el mejor momento de hacer una invitación especial a la familia que se está visitando. Una de las formas más efectivas es preguntar a aquellos; cuya fe está deteriorada, aquellos que se han apartado de la fe por algún tiempo o aquellos que conocen, pero están demorando en tomar la decisión de entrega 
a Dios. El motivo de la visita es porque el pastor desea la salvación de esta familia. Por lo tanto, se les debe animar a tomar decisiones para salvación. El pastor debe comprender que él es responsable de conducir a las familias en alcanzar su salvación.

b. Por lo tanto, los padres deben entender que ellos son responsables por la salvación de sus hijos. Este es el mejor momento de fortalecer los lazos familiares y de animarlos a estudiar la Biblia juntos, en procura de recibir ayuda mutua dentro de ese círculo familiar (Mal 4:6).

c. Si toda la familia está involucrada en la actividad misionera, agradecer a Dios porque la influencia de esa familia contribuye a la salvación de las personas en la iglesia.
Después de haber realizado todas las preguntas y de haber conducido a la hermandad por el camino de la salvación, llegó el momento más importante de la visitación. Es el momento de hacer los pedidos de oración. El pastor debe preguntar, a cada uno de los integrantes de la familia, por sus pedidos de oración. Si la familia no se mostró muy sincera con sus respuestas en las preguntas anteriores, en los pedidos de oración el pastor podrá enfocarse en el problema principal de aquella familia, por lo cual la oración debe ser realizada con mucha solemnidad.

Para finalizar la visita, el pastor debe dejar una tarea a cada uno de los integrantes de la familia, así como el médico realiza un diagnóstico, el pastor ya tiene el diagnóstico, ahora tiene que dejar el remedio para ellos. Además, el pastor les debe dar un plazo de un mes o dos meses como máximo para mejorar su vida espiritual y reorientar su vida. Después de finalizar la visitación, el pastor debe salir de esa casa para que la familia se quede con el mensaje final del pastor. 


\section{Conclusiones}

El arte de la visitación puede determinar el éxito o fracaso del pastor distrital, una de las ventajas que el pastor puede obtener, como resultado de la visitación, es el que el miembro de iglesia no se relacionará con él por el cargo, sino como su amigo. Como aquel amigo que Dios envió para permitir la salvación de su congregación.

La visitación es un diagnóstico espiritual realizado por el pastor a los miembros de iglesia, para acercarlos a Jesús. Si el pastor logra que los miembros de iglesia alcancen la dependencia de Jesús, entonces tendrá un ministerio fructífero.

Son siete las preguntas que son fundamentales para realizar un buen diagnóstico espiritual: Fecha de bautismo, culto familiar, recibimiento de sábado, devolución de los diezmos, ofrendas, promesas y actividad misionera. Probablemente no sean las únicas preguntas, pero en la experiencia del autor de este artículo estas preguntas fueron suficientes y necesarias para desarrollar un buen diagnóstico, y por ende, una buena visitación. Las consecuencias de tomar tiempo en hacer este tipo de visitación, en cada miembro de iglesia, es sin precedentes. En primer lugar, la vida del creyente es mejorado de una forma integral, se esforzará por alcanzar y mantener una buena vida espiritual. Podrá experimentar las bendiciones de Dios en todas las áreas de su vida. La iglesia crecerá y desarrollará en aspectos como: el nivel de compromiso misionero aumentará, la fidelidad en la devolución de los diezmos será multiplicado, la entrega de las ofrendas crecerá exponencialmente, el dinero para los proyectos de iglesia aumentará de forma significativa y los bautismos serán multiplicados, sin necesidad de hacer gasto alguno.

A qué pastor no le gustaría tener una iglesia con las características mencionadas. Para alcanzar este desafío, es necesario realizar la visitación como una prioridad en su ministerio, hay un sacrificio en terminar de hacer las visitaciones a los miembros de iglesia, pero después cosechará los frutos y tendrá tiempo para desarrollar otras áreas de la iglesia. 